\title{
The Comprehensive Economic Contribution of China's Tourism Trade Export
}

\author{
Yi Liu, Wendi Li \\ School of Management, Jinan University, Guangzhou, China \\ Email: wendyylee@sina.cn
}

How to cite this paper: Liu, Y. and $\mathrm{Li}$, W.D. (2019) The Comprehensive Economic Contribution of China's Tourism Trade Export. Modern Economy, 10, 1095-1106. https://doi.org/10.4236/me.2019.104074

Received: March 7, 2019

Accepted: April 6, 2019

Published: April 9, 2019

Copyright $\odot 2019$ by author(s) and Scientific Research Publishing Inc. This work is licensed under the Creative Commons Attribution International License (CC BY 4.0).

http://creativecommons.org/licenses/by/4.0/

\section{c) (i) Open Access}

\begin{abstract}
International tourism trade plays an important role in earning foreign exchange through export. At the same time, this industry has a clear and single source of income, which enables relevant industrial policies to play a more effective guiding role. Thoroughly understanding the important role of China's tourism export to economic growth, can help formulate industrial policies with theoretical basis and practical pertinence. However, there is still a lack of relevant research. In order to fill this gap, the author uses input-output analysis to calculate the comprehensive economic contribution of China's tourism export, and its internal structure is analyzed. The results show that in 2016, the export of tourism trade achieved a direct added value of 317.658 billion yuan, and the complete added value driven by industrial spreading effect reached 796.734 billion yuan, accounting for $1.07 \%$ of GDP, which affirmed the strong economic pulling role of tourism export. According to the internal structure of complete added value, this paper suggests industrial policy should give priorities to support the development of tourism merchandise manufacturing, accommodation and catering sectors, guiding inbound tourists to increase the consumption in the above three items, so as to optimize the income structure and improve the comprehensive economic benefits of tourism trade export.
\end{abstract}

\section{Keywords}

Tourism Trade Export, Complete Added Value, Input-Output Analysis

\section{Introduction}

Tourism trade export plays an important role in China's service trade export. Compared with other service export industries, tourism export has a clearer source of income, that is, the consumption expenditure of inbound tourists. This 
characteristic enables government-led industrial policies to be a more effective role in guiding and regulating the export of tourism. According to the data from National Tourism Data Center [1], in 2016, China's tourism export reached 120 billion US dollars, accounting for $57.61 \%$ of total service trade export income. At the same time, tourism imports also reached 109.8 billion US dollars [1], so the favorable balance of trade was only 10.2 billion US dollars. Therefore, although China's tourism trade is large in scale, due to the small surplus and even the deficit in some years, the role of tourism export in economic growth has not been fully understood and recognized.

At present, most research on tourism export concentrated on two aspects: first, research on the competitive power of tourism trade, and second, research on the relationship between inbound tourism and economic growth. However, which method is suitable for calculating and evaluating the comprehensive economic contribution of tourism export from the perspective of industrial economics? And what's the characteristic of its economic pulling effect? The above questions remain unanswered.

Comprehensive economic contribution means that the added value created by tourism trade export not only directly contributes to economic growth, but also drives the development of various industrial sectors which is directly or indirectly related to it through industrial spreading effect, thus creating indirect added value. The sum of direct added value and indirect added value is the complete added value, reflecting the comprehensive contribution of tourism export to economic growth. Calculating the comprehensive contribution and analyzing its internal structure of tourism export not only help to thoroughly understand the significant role of tourism export in China's economic growth, but also provide theoretical basis for formulating targeted industrial policies to promote China's inbound tourism development. Therefore, by using the input-output analysis model, this paper calculates the direct added value and complete added value of China's tourism export in 2016, and then analyzes its internal structure. Finally corresponding implications and suggestions are put forward.

\section{Literature Review}

\subsection{Research on Tourism Industry's Economic Contribution}

Since the beginning of the $21^{\text {st }}$ century, under the continuous expansion of the tourism industry, tourism's economic contribution has begun to receive extensive attention form tourism research. Scholars mainly use the three methods to measure the economic contribution of tourism industry. Namely, tourism added value, tourism satellite account and input-output analysis.

The method of tourism added value is base on the internal structure of tourists' consumption and the consumption detachment coefficient. To be specific, firstly detach the added value created by tourism consumption in each industry sector involved in tourism, secondly summarize each added value form the individual sectors, then get the total direct added value, that is, direct economic con- 
tribution of tourism. For example, Li et al. took the lead in calculating the added value of tourism industry of 19 provinces in China, 1996 [2]. Wei et al. estimated the added value of tourism industry in Hubei province from 1996 to 2001 by assuming that the tourism consumption detachment coefficient remained unchanged in a certain period [3]. Zeng et al. also estimated the added value of tourism industry of 31 provinces from 2000 to 2008 by using the same method [4].

As for tourism satellite account (TSA), it is a virtual subsidiary account beyond the existing System of National Accounts (SNA). TSA is set up according to the SNA criteria, the output generated by tourists' consumption is detached from the relevant economic sectors and listed in this virtual account. Thus, TSA is able to use for measuring the contribution rate of tourism industry to GDP, in addition enables tourism industry to be a comparison of other economic sectors in SNA. Chinese scholars have introduced the principles, functions and development methods of TSA [5]. Practically, Xiamen, Jiangsu, Zhejiang and other provinces and cities have also set up regional TSA. However, while TSA can measure tourism industry's direct economic contribution, it's not able to measure comprehensive contribution.

Input-output analysis method is based on SNA's input-output model defined from the perspective of "production". The input-output table reveals the final demand of tourists so it is able to use for calculating the direct and indirect output of tourism industry, in order words the direct and indirect tourism added value. Since the 1990s, this method has been widely used in relevant research. For example, Archer, Henry et al. and Williams respectively measured the comprehensive contribution of tourism in Bermuda, Ireland and a seaside town in Australia to the regional total output [6] [7] [8]. Fletcher et al. discussed the difference in the economic contribution caused by different tourism market in Seychelles [9]. Sanchez et al. focused on the Holy Week festival, measured the economic contribution of tourism to Palencia, Spain during the festival [10]. Zhou et al. used the calculable general equilibrium model (CGE) extended from the input-output model to measure the economic impact brought by the decrease in tourism consumption in Hawaii [11].

Among the above three methods, TSA is the most rigorous methods for measuring tourism added value, however it cannot calculate tourism industry's comprehensive economic contribution. Besides, it has a huge workload in sampling survey and data collection. Relatively speaking, input-output analysis can calculate both direct and comprehensive economic contribution of tourism industry, and the required basic data is easier to obtain. At the same time, the research using input-output analysis has been relatively mature, so it is a sound analytical tool. In sum, input-output analysis has a comparative advantage in the research of tourism industry's economic contribution.

\subsection{Research on Relationship between Tourism Export and Economic Growth}

At present, the empirical study on relationship between tourism export and 
economic growth mainly adopted econometric methods such as Cointegration Test and Granger Causality Test on the data of GDP, inbound tourism income and number of inbound tourists. Among the relevant research, the scholars failed to reach an agreement on the mentioned relationship. For instance, Eeckels et al. and Liu respectively verified that inbound tourism would lead to economic growth in Greece and China [12] [13]. Oh, Huang et al. and Cortés Jimenez et al. studied the case of South Korea, Tunisia and China respectively, only came to the conclusion that economic growth drives the development of inbound tourism [14] [15] [16]. Kim et al. and Nowak et al. in their studies on Taiwan and Spain respectively, held the view that inbound tourism and economic growth are mutually promoting [17] [18]. Other studies have shown that the different selection of proxy variables, regional differences and the influence of economic periods and events are the reasons for the above different conclusions [19] [20].

\subsection{Space for Further Research}

To sum up the above literature, the current research on tourism export and economic growth rarely focused on the comprehensive economic contribution of tourism export. Moreover, most studies only discussed the overall index of inbound tourism income without considering its internal structure, thus fail to reveal the characteristics and differences among each economic sectors. Therefore, this paper adopts the input-output analysis method to study the direct and comprehensive economic contribution of tourism export, and further reveals the pulling mechanism of tourism export to economic growth by analyzing the structural characteristics of the comprehensive contribution.

\section{Data Source and Measurement Methods}

\subsection{Data Source Description}

The original data in this paper are all second-hand data published officially, including the input-output table of 139 economic sectors published by China National Bureau of Statistics in 2012 [21], and the inbound tourism income in 2016 revealed in China Statistical Yearbook [22]. The income structure comes from the sample survey data of the China National Tourism Administration (CNTA) on the inbound tourists [23].

Inbound tourism income includes nine items, namely long-distance transportation, sightseeing, accommodation, catering, merchandise sales, entertainment, post and telecommunications, urban transportation and other services. Except for merchandise sales, the other eight items can directly correspond to the economic sectors in the input-output table. Since there is no subdivision of the merchandise sales income among the official data, this paper classifies its internal structure according to the shopping willingness data of inbound tourists in the questionnaire designed by CNTA, and then selects the corresponding economic sectors to the inbound tourists' shopping consumption from input-output 
table. In addition, due to the merchandise sales involve both manufacture and distribution segments, respectively correspond to manufacturing sectors and wholesaling/retailing sector. Therefore, we need to separate the merchandise sales into two items, namely commodity manufacture and commodity distribution, by using national wholesale/retail industry's average gross margin.

According to the subdivided structure of inbound tourism income, 23 corresponding economic sectors are selected from the input-output table, and then merge specific sectors according to research needs (see Table 1). Finally get the 12 economic sectors which are directly related to tourism industry as well as the input-output table including 127 economic sectors.

\subsection{Measurement Methods and Models}

Firstly, according to the basic matrix of the input-output table, the added value rate of the 12 economic sectors that directly related to the tourism export is calculated. Combined with the corresponding inbound tourism income, the direct added value $V_{1}$ of tourism export is summarized to reflect the direct economic contribution. Formula is as follows.

$$
V_{1}=\sum c_{i} r_{i}
$$

The above $i=1,2, \cdots, 12$, represents the economic sectors that directly related

Table 1. Economic sectors that directly related to tourism export.

\begin{tabular}{|c|c|c|}
\hline Items of Inbound Tourism Income & $\begin{array}{l}\text { Corresponding Economic Sectors } \\
\text { in Input-Output Table }\end{array}$ & Notes \\
\hline \multicolumn{3}{|l|}{ Long-distance Transportation } \\
\hline Civil Aviation & Air Transport & - \\
\hline Railway & Railway Transport & - \\
\hline Car & Road Transport & - \\
\hline Ship & Water Transport & - \\
\hline Sightseeing & Public Facilities Management; Culture/Art & Merge as Sightseeing \\
\hline Accommodation & Accommodation & - \\
\hline Catering & Catering & - \\
\hline \multicolumn{3}{|l|}{ Merchandise Sales } \\
\hline Commodity Distribution & Wholesale/Retail & - \\
\hline Commodity Manufacture & $\begin{array}{l}\text { Other foods; Alcohol; Beverages and refined tea; Tobacco; Hemp and silk textiles; } \\
\text { Textile clothing; Articles for culture, education, works of art, sports and } \\
\text { entertainment; Pharmaceutical products; Ceramic products; Culture/office-used } \\
\text { machinery; Home appliances }\end{array}$ & $\begin{array}{l}\text { Merge as Commodity } \\
\text { Manufacture }\end{array}$ \\
\hline Entertainment & Entertainment & - \\
\hline Post and telecommunication & Postal service; Telecommunications and other information transmission services & $\begin{array}{l}\text { Merge as Post and } \\
\text { telecommunication }\end{array}$ \\
\hline Urban Transportation & Road Transport & - \\
\hline Other Services & Service for Residents & - \\
\hline Total Number & 23 & 12 \\
\hline
\end{tabular}

National wholesale/retail industry's average gross margin in 2016 is 0.386 . 
to the tourism export. While $c_{i}$ represents the output caused by inbound tourism consumption of the $i^{\text {th }}$ sector, and $r_{i}$ represents the added value rate of the $i^{\text {th }}$ sector.

Secondly, the calculation of indirect added value applies the concept of Complete Consumption in input-output analysis, which refers to the total consumption of a product for another economic sector when it is produced [24]. Using complete consumption coefficient matrix of the input-output table, the complete consumption of other sectors caused by the output of sectors that directly related to tourism export can be calculated, that is, the intermediate input of other sectors which is required during the production of tourism industry. Combined with the added value rate of each sector in the national economy, the total indirect added value $\left(V_{2}\right)$ generated by tourism export can be calculated, reflecting the indirect economic contribution. Formula is as follows.

$$
\begin{gathered}
V_{2}=\sum X_{i} \\
X_{i}=\sum c_{i} b_{j i} r_{j}
\end{gathered}
$$

The above $i=1,2, \cdots, 12$, represents economic sectors that directly related to tourism export, and $\mathrm{j}=1,2, \cdots, 127$, represents all economic sectors in the input-output table. And $c_{i}$ is the output of the $I^{\text {th }}$ sector that directly caused by inbound tourism income. While $b_{j i}$ is the complete consumption coefficient, represents the complete consumption for the $f^{\text {th }}$ sector when the $I^{\text {th }}$ sector produces 1 unit product. And $r_{i}$ is the added value rate of the $f^{\text {th }}$ sector. Thus $X_{i}$ is the total output of all sectors in the national economy caused by the $i^{\text {th }}$ sector through industrial spreading effect.

The complete added value $(V$ ) calculated by summing up the direct added value and the indirect added value reflects the comprehensive economic contribution of tourism export. Formula is as follow.

$$
V=V_{1}+V_{2}
$$

\section{Calculation Results and Analysis}

\subsection{Calculation of Direct Added Value}

Firstly, according to formula (1), it is calculated that in 2016, China's tourism trade export created a direct added value of 317.658 billion yuan, among which the direct contributions of transportation, wholesale/retail and accommodation sectors are the largest, the sum of the three sectors accounted for $52.48 \%$ of the total direct added value. The detail data is shown in Table 2.

\subsection{Calculation of Complete Added Value}

According to formula (2), (3) and (4), it is calculated that China's tourism export in 2016 triggered a complete added value of 796.734 billion yuan, accounting for $1.07 \%$ of GDP, reflecting its comprehensive contribution to economic growth. As shown in Table 3 , the direct added value accounts for $0.43 \%$ of GDP, indicating that the indirect contribution generated through industrial spreading ef- 
fect exceeds the direct contribution.

In addition, the internal structure of direct and indirect added values contributed by the economic sectors that directly related to tourism export is shown in Table 4.

\subsection{Analysis on Tourism Industry's Driving Capacity}

Among the total comprehensive contribution, the share caused by each economic sector that directly related to tourism export reflects its driving function on various industries in the national economy. However, this share is only directly related to inbound tourists' consumption structure, but does not represent the sector's industrial driving capacity. Therefore, industrial influence, an indicator reflecting the industrial driving capacity of the economic sector itself, was introduced. By comparing the consumption structure of transportation, accommodation, catering, sightseeing, entertainment, shopping and the industrial

Table 2. Direct added value of China's tourism export in 2016.

\begin{tabular}{cccc}
\hline $\begin{array}{c}\text { Economic Sectors that } \\
\text { Directly Related to } \\
\text { Tourism Export }\end{array}$ & $\begin{array}{c}\text { Inbound Tourism } \\
\text { Income (Billion US } \\
\text { Dollars) }\end{array}$ & Value Added Rate & $\begin{array}{c}\text { Direct Added Value of } \\
\text { Tourism Export } \\
\text { (Hundred Million RMB) }\end{array}$ \\
\hline $\begin{array}{c}\text { Air Transport } \\
\text { Railway Transport }\end{array}$ & 290.60 & 0.239 & 461.47 \\
Road Transport & 73.20 & 0.498 & 175.82 \\
Water Transport & 71.00 & 0.402 & 192.06 \\
Sightseeing & 67.10 & 0.297 & 140.03 \\
Accommodation & 116.30 & 0.439 & 195.72 \\
Catering & 96.20 & 0.423 & 326.82 \\
Wholesale/Retail & 80.90 & 0.405 & 258.62 \\
Commodity & 128.60 & 0.691 & 370.98 \\
Manufacture & 77.10 & 0.260 & 222.13 \\
Entertainment & 28.90 & 0.546 & 279.36 \\
Post and & 118.00 & 0.541 & 103.87 \\
Telecommunication & 1200.00 & 0.574 & 449.71 \\
Service for Residents & & - & 3176.58 \\
Total & & & \\
\hline
\end{tabular}

The exchange rate of RMB against the US dollar is translated according to the 2016 annual average price (6.64) published by the World Bank's WDI database.

Table 3. Comprehensive economic contribution of China's tourism trade in 2016.

\begin{tabular}{cccc}
\hline \multicolumn{2}{c}{ Direct Added Value } & \multicolumn{2}{c}{ Complete Added Value } \\
\hline $\begin{array}{c}\text { Total Amount } \\
\text { (hundred million yuan) }\end{array}$ & Percentage of GDP & $\begin{array}{c}\text { Total Amount } \\
\text { (hundred million yuan) }\end{array}$ & Percentage of GDP \\
\hline 3176.58 & $0.43 \%$ & 7967.34 & $1.07 \%$ \\
\hline
\end{tabular}


Table 4. Internal structure of the comprehensive economic contribution.

\begin{tabular}{ccc}
\hline $\begin{array}{c}\text { Economic Sectors that Directly } \\
\text { Related to Tourism Export }\end{array}$ & $\begin{array}{c}\text { Percentage of Direct } \\
\text { Contribution }\end{array}$ & $\begin{array}{c}\text { Percentage of Comprehensive } \\
\text { Contribution }\end{array}$ \\
\hline Air Transport & $14.5 \%$ & $24.2 \%$ \\
Railway Transport & $5.5 \%$ & $4.4 \%$ \\
Road Transport & $6.1 \%$ & $6.0 \%$ \\
Water Transport & $4.4 \%$ & $6.0 \%$ \\
Sightseeing & $6.2 \%$ & $5.6 \%$ \\
Accommodation & $10.3 \%$ & $9.7 \%$ \\
Catering & $8.1 \%$ & $8.0 \%$ \\
Wholesale/Retail & $11.7 \%$ & $6.7 \%$ \\
Commodity Manufacture & $7.0 \%$ & $10.7 \%$ \\
Entertainment & $8.8 \%$ & $6.4 \%$ \\
Post and Telecommunication & $3.3 \%$ & $2.4 \%$ \\
Service for Residents & $14.2 \%$ & $9.8 \%$ \\
Total & $100 \%$ & $100 \%$ \\
\hline
\end{tabular}

influence of their corresponding sectors, this paper further analyzes the characteristics of the internal structure of the comprehensive contribution and its implication for promoting the development of inbound tourism.

Industrial influence refers to the total demand for the products of all sectors in the national economy from one unit final product produced by an industrial sector [24]. For example, the influence of the air transport sector is 3.35, which means that every unit of final product produced by the air transport sector will boost the output of the entire national economy by 3.35 units. The formula is as follows.

$$
I_{j}=\sum \bar{b}_{i j}
$$

The above $i=1,2, \cdots, 12$, represents the economic sectors that directly related to tourism export, and $j=1,2, \cdots, 127$, represents all economic sectors in the input-output table, while $\bar{b}_{i j}$ is the Leontief coefficient in the input-output table.

The calculation results are shown in Table 5. Generally speaking, the proportion of the six main consumption items (transportation, accommodation, catering, sightseeing, entertainment and shopping) in total expenditure has a good matching degree with the industrial influence of the corresponding economic sectors, indicating that the consumption structure of inbound tourists in China is getting optimized.

Among Table 5, the industrial influence of each kind of transportation sectors is generally high, especially the air transportation, whose industrial influence ranks first at 3.35. However, as the rigidity of traffic consumption is relatively large, so the promotion space of traffic consumption's proportion is quite limited. As for shopping consumption, the industrial influence of tourism commodity 
Table 5. Comparison of consumption structure and industrial influence.

\begin{tabular}{cccc}
\hline $\begin{array}{c}\text { Main Items of Inbound } \\
\text { Tourists' Consumption }\end{array}$ & $\begin{array}{c}\text { Corresponding Economic } \\
\text { Sectors }\end{array}$ & $\begin{array}{c}\text { Percentage of } \\
\text { Consumption }\end{array}$ & $\begin{array}{c}\text { Corresponding } \\
\text { Industrial Influence }\end{array}$ \\
\hline \multirow{3}{*}{ Transportation } & Air Transport & $24.2 \%$ & 3.35 \\
& Road Transport & $6.0 \%$ & 2.74 \\
& Water Transport & $5.9 \%$ & 3.02 \\
& Railway Transport & $4.4 \%$ & 2.45 \\
Shopping & Wholesale/Retail & $10.7 \%$ & 3.29 \\
Accommodation & Commodity Manufacture & $6.8 \%$ & 1.80 \\
Catering & Accommodation & $9.7 \%$ & 2.66 \\
Entertainment & Catering & $8.0 \%$ & 2.61 \\
Sightseeing & Entertainment & $6.4 \%$ & 2.26 \\
\hline
\end{tabular}

manufacturing is only second to that of air transport, which is 3.02 , and has the highest influence among the corresponding sectors of flexible spending. This result provides a reasonable basis for optimizing the income structure of China's tourism export by increasing the proportion of shopping consumption of inbound tourists. The industrial influence of the accommodation sector and the catering sector is 2.66 and 2.61 respectively. Since both the accommodation and catering consumption have certain elasticity, it is also of positive significance to appropriately increase the proportion of these two items of consumption in promoting economic growth. The industry influence of scenic spot and entertainment departments is relatively low, which is 2.58 and 2.26 respectively, and their corresponding consumption proportion is the lowest among the six main consumption items.

\section{Conclusions and Implications}

\subsection{Research Conclusions}

This paper utilizes input-output table and international tourism income from official statistics, adopts the input-output analysis method to study the comprehensive economic contribution of China's tourism export in 2016, then gets the following conclusions.

First, China's tourism export contributed 317.658 billion yuan of direct added value to economic growth, accounting for $0.43 \%$ of GDP in 2016 . Taking into account the industrial spreading effect among various economic sectors, through indirectly driving the development of other sectors, the tourism industry finally created a complete added value of 796.734 billion yuan, accounting for $1.07 \%$ of GDP. The indirect contribution is larger than the direct contribution, which affirms the strong driving effect of tourism export on the national economy. If the indirect contribution is ignored, the contribution of tourism export to economic growth will be greatly underestimated. 
Second, among the economic sectors that correspond to the flexible consumption of inbound tourists, the tourism commodity manufacturing sector directly related to shopping consumption has the greatest industrial driving capacity, Therefore, it is of great significance to give priority to the promotion of the shopping consumption proportion of inbound tourists, so as to increase the comprehensive contribution caused by the tourism commodity manufacturing sector, so that it gives full play to the large driving capacity of this sector. In addition, the industry influence of accommodation and catering sectors is also relatively large. Therefore, properly guiding inbound tourists to increase the proportion of accommodation and catering expenditure also plays a positive role in maximizing the comprehensive economic effect of tourism trade export.

\subsection{Research Implications}

The above conclusions provide a theoretical basis for fully understanding the industrial status of China's tourism export, using industrial policies to optimize the inbound tourism income structure, and maximizing its comprehensive economic effect. The specific implications are as follow.

First, vigorously develop inbound tourism and continuously increase the total amount of foreign exchange earned by tourism. China's tourism export plays a powerful role in driving the economy. We should fully recognize and attach importance to its industrial status, enhance the competitiveness of inbound tourism, seize the opportunity of the "One Belt And One Road" initiative, and attract more inbound tourists from countries along the "One Belt And One Road".

Second, optimize the structure of inbound tourism consumption to maximize the role of tourism export in driving economic growth. In order to give full play to the relatively large industrial driving function of tourism commodities, accommodation and catering sectors, priority should be given to guiding the increase of shopping, accommodation and catering consumption of inbound tourists.

Third, in terms of industrial development policies, we should focus on improving the quality of tourist commodities and further improve the tourism shopping consumption environment, such as promoting the acceptance of electronic payment in line with international standards and the development of online tax refund business, so as to provide safe and convenient shopping consumption experience for inbound tourists. At the same time, we should promote innovation in the accommodation and catering industries, develop more distinctive accommodation and catering products and services, so as to provide more diversified choices for inbound tourists.

\section{Conflicts of Interest}

The authors declare no conflicts of interest regarding the publication of this paper.

\section{References}

[1] National Tourism Data Center (2018) Trade in Tourism Services Continued to Run 
a Surplus. http://zwgk.mct.gov.cn/auto255/201802/t20180205_832374.html

[2] Li, J.F. and Li, M.Y. (1999) Tourism Industry and Measurement of Tourism Added value. Tourism Tribune, 5, 16-19.

[3] Wei, W. and Chen, X.J. (2006) Comprehensive Evaluation and Analysis of Economic Contribution of Tourism Industry. Economic Geography, 2, 331-334.

[4] Zeng, G.J. and Cai, J.D. (2012) Research on the Contribution of China's Tourism Industry to the National Economy. Tourism Tribune, 5, 23-31.

[5] Ge, Y.J. (2007) The Development and Methodology of Tourism Satellite Account (TSA). Tourism Tribune, No. 7, 11-18.

[6] Archer, B. (1995) Importance of Tourism for the Economy of Bermuda. Annals of Tourism Research, 22, 918-930. https://doi.org/10.1016/0160-7383(95)00018-1

[7] Henry, E.W. and Deane, B. (1997) The Contribution of Tourism to the Economy of Ireland in 1990 and 1995. Tourism Management, 18, 535-553. https://doi.org/10.1016/S0261-5177(97)00083-6

[8] Williams, G. (2016) Economic Impacts from Development of the Coastal Town in Queensland on Tourism and Regional Economy. Resources, 5, 48. https://doi.org/10.3390/resources5040048

[9] Archer, B. and Fletcher, J. (1996) The Economic Impact of Tourism in the Seychelles. Annals of Tourism Research, 23, 32-47. https://doi.org/10.1016/0160-7383(95)00041-0

[10] Sánchez, V.L., Fernández, M.D. and Lara, J.Á.S. (2016) Economic Impact of a Religious and Tourist Event: A Holy Week Celebration. Tourism Economics, 23, 1255-1274. https://doi.org/10.1177/1354816616675996

[11] Zhou, D., Yanagida, J.F., Chakravorty, U. and Leung, P. (1997) Estimating Economic Impacts from Tourism. Annals of Tourism Research, 24, 76-89. https://doi.org/10.1016/S0160-7383(96)00035-7

[12] Eeckels, B., Filis, G. and Leon, C. (2012) Tourism Income and Economic Growth in Greece: Empirical Evidence from Their Cyclical Components. Tourism Economics, 18, 817-834. https://doi.org/10.5367/te.2012.0148

[13] Liu, C.J. and Feng, X.G. (2014) Relationship between Inbound Tourism Development and China's Economic Growth. Economic Management, 2, 125-135.

[14] Oh, C. (2005) The Contribution of Tourism Development to Economic Growth in the Korean Economy. Tourism Management, 26, 39-44. https://doi.org/10.1016/j.tourman.2003.09.014

[15] Huang, W.L. and An, L. (2010) Empirical Test of the Relationship between Inbound Tourism Development and China's Economic Growth Dynamics. Statistics and Decision-Making, 2, 92-94.

[16] Cortés-Jiménez, I., Nowak, J. and Sahli, M. (2011) Mass Beach Tourism and Economic Growth: Lessons from Tunisia. Tourism Economics, 17, 531-547. https://doi.org/10.5367/te.2011.0047

[17] Kim, H.J., Chen, M. and Jang, S.S. (2006) Tourism Expansion and Economic Development: The Case of Taiwan. Tourism Management, 27, 925-933. https://doi.org/10.1016/j.tourman.2005.05.011

[18] Nowak, J., Sahli, M. and Cortés-Jiménez, I. (2007) Tourism, Capital Good Imports and Economic Growth: Theory and Evidence for Spain. Tourism Economics, 13, 515-536. https://doi.org/10.5367/000000007782696113

[19] Tugcu, C.T. (2014) Tourism and Economic Growth Nexus Revisited: A Panel Cau- 
sality Analysis for the Case of the Mediterranean Region. Tourism Management, 42, 207-212. https://doi.org/10.1016/j.tourman.2013.12.007

[20] Antonakakis, N., Dragouni, M. and Filis, G. (2015) How Strong Is the Llinkage between Tourism and Economic Growth in Europe? Economic Modelling, 44 142-155.

[21] China National Bureau of Statistics (2015) China Input-Output Table 2012. China Statistics Press, Beijing.

[22] China National Bureau of Statistics (2017) China Statistical Yearbook 2017. China Statistics Press, Beijing.

[23] China National Tourism Administration (2017) Tourism Sample Survey Data 2017. China Travel \& Tourism Press, Beijing.

[24] Liu, Q.Y., Chen, Z. and Su, R. (2006) Input-output Analysis. China Renmin University Press, Beijing. 